\title{
Implementation of Open Performance Review and Appraisal System in Tanzania Local Government Authorities: Some Observations and Remarks
}

\author{
Ausi Nchimbi \\ Tanzania Public Service College, PO box 1534, Singida, Tanzania
}

\begin{abstract}
Open Performance Review and Appraisal System (OPRAS) was introduced by the Tanzania government in 2004 as a new innovation for managing individual's performance in the Tanzania public service. OPRAS is viewed as an idiosyncratic tool in the history of Human Resource Management (HRM) in the Tanzanian public service among other tools for managing performance in the public service. OPRAS as proposed by Performance Improvement Model (PIM) is important to the adoption and nurturing of the performance management culture in the public service. Nevertheless, sketchy evidence reveals that despite the Government efforts to introduce OPRAS, it has not been in a position to develop a real and effective Open Performance Review and Appraisal System. With this in mind, this study intended to evaluate whether OPRAS as currently used in IDC (a focus of this study) is adequate to improve employees' performance. The study employed a cross-sectional research design. A sample of 80 respondents was used. Data was collected through questionnaires and interviews. The data collected were analyzed and processed by use of SPSS computer software and descriptive statistics such as frequencies, percentages and tables were presented. The findings suggest that majority of participants reported that OPRAS as currently used in IDC is not adequate at improving employees' performance.
\end{abstract}

Keywords: Local Government Authorities, Performance Management, OPRAS

DOI: $10.7176 / \mathrm{JAAS} / 53-05$

Publication date:March $31^{\text {st }} 2019$

\section{Introduction}

The public sector reform drive was initiated under several names, one of which is New Public Management (NPM). These reforms came to existence during the 1980's in the advanced capitalist nations as a response to the economic crisis (Gregory, 2001). With the glowing number of challenges faced today, there are now, more than ever, increased demands on managers and all other staff members to achieve higher levels of efficiency and productivity. The continuously changing nature of most public services today and the higher expectations from the general public have increased pressure on public servants to re-evaluate their contributions in their work places and the way in which they work. The introduction of performance management systems has been one of the strategies adopted to meet this challenge (Mgoma, 2010).

Performance management system are amongst the most important human resource practices and also continue to be the subject of interest and importance to human resource subject both in theory and practice. Performance management is vital for survival and profitability of the firm in the market place. High performing employees contribute to the superior performance giving the firm they work a competitive advantage and their extra effort provide the firm with distinctive capability. In the public service also performance management has become a popular subject. The pressure to maximize result and quality in Public Service in most countries in the world has resulted to the adoption of NPM principles which bear a resemblance to many management techniques from the private sector.

Under NPM, public institutions like private institutions are required to justify their spending on productive resources in a transparent and measurable way. In NPM performance management is an overarching focus. The use of performance management tools is frequently recommended by the literature in the field of management (Davis and Albright, 2004; Armstrong, 2009; Panda, 2011; Hildebrand, 2007; Buchner 2007). Government at all levels in Tanzania, similar to other public sector organizations in the World, has been going through prolonged and dramatic system changes that institute performance culture. These include socio-economic and legal changes that call for doing things differently compared to the past.

Tanzania has undertaken considerable reforms in managing public sector in the shape of NPM. Among other things, performance management constitutes the core focus of Tanzanian's public service reform agenda (Bana, 2009). The Public Service Reform Program (PSRP) introduced by Tanzanian Government in 2000 aimed at improving public service delivery and policy management. In fact, every public organization is required to introduce performance management system so as to improve efficiency and effectiveness of its service delivery and to ensure that value for money is achieved (Bana, 2009; Sulle, 2014; Rugumyamheto, 2005).

The cradle of Performance Management in Tanzania Public Service is the reform agenda. Since 1961 when Tanzania attained its political independence, the government took deliberate actions to reform the civil or public 
service in order to spearhead development in the economic and social spheres to respond to the expectations of the people. The public service was viewed as a strong arm of the government as well as engine for growth and development and was expected to ensure that the war against three development enemies was executed to a successful end (Bana, 2009).

It is in the above context that, the government of Tanzania introduced Open Performance Review and Appraisal System in all Ministries, Departments and agencies (MDAs), Regional secretariats and Local Government Authorities(LGAs) to enable proper and more effective use of human capital (PO-PSM, 2011). The tool (OPRAS) replaced the old performance management system. The tool hoped to bring accountability and effectiveness in public service delivery. However, comprehensive literature review indicates that there is a rising doubts about the implementation efforts of OPRAS. If these doubts are true, it is not hard to conclude that OPRAS in Tanzania may not bring about the intended results as expected.

Moreover, a heuristic review of the literature uncovered very few published studies on the implementation of OPRAS in Tanzania especially in Local Government Authorities but even the quick review of the available studies expose the overriding focus on the implementation in MDAs. This study departs from that direction and appeals to evaluate the utilization of OPRAS in LGAs in Tanzania to see whether OPRAS as currently used in LGAs is adequate for improving employees' performance. The extent to which local governments have experienced success and challenges is the key issue of this study.

\subsection{Literature Review}

\subsection{Theoretical Literature Review}

\subsubsection{Performance management and Performance Appraisal: Understanding the Concepts}

Performance management has become a focus of discussion in the management literature today. According to Armstrong (2009) performance management is a means of getting better results by understanding and managing performance within an agreed framework of planned goals, standards and competency requirements. The ultimate objective of performance management process is to align individual performance with the organizational performance; the process of performance management should signifies employees about the organization's goals, priorities and expectations and how well they are contributing to them. Any performance management system should aim to develop the capacity of the people to meet and exceed expectations and achieve their full potentials to the benefit of themselves, the organization and the society in general.

It is difficult to trace the true antecedent of formal performance management appraisal but it seems that the performance appraisals of workers on annual basis began with the advent of industrial revolution in the late of $18^{\text {th }}$ century (Kohli, 2008 in Panda, 2011). The basic purpose was to assess the productivity of workers. The rating of performance was introduced in the 1920s. The focus of appraisal changed to assessing the personality traits of workers after the Hawthorne studies. This brought a merit rating method for assessing performance.

However, this method came under severe criticism as it focused more on the personality traits. Moreover, trait measures were subjective and dubious in predicting the outcome of employees (Napier \& Latham, 1986 in Panda, 2011). From there Management by Objective (henceforth MBO) approach as advocated by Peter Druncker (1956) gained popularity in the management field. However, its being too much subjective and inconsistency made it an approach that is limited to performance management.

For the first time the phrase of performance management was used by Beer and Ruth (1976) (Kohli, 2008 cited in Panda, 2011). The concept has been the most significant development in the field of Human Resource Management (HRM) in recent time. The emphasis has been shifting from controlling, commanding and vigilant system to commitment based system. According to Armstrong and Angela (2005) performance management is a process which contributes to the effective management of individuals and teams in order to achieve high levels of organizational performance. The process of managing performance is similar to the models used to manage performance at the organizational level (Selden et al, 2011). They further argued that the process starts at the top of the organization with management developing a performance management policy. Managers primarily control performance by influencing inputs and by the feedback provided.

Performance management should be a planned process of which the five primary elements are agreements, measurement, positive reinforcement and dialogue. It is concerned with measuring outcomes in the shape of delivered performance compared with expectations expressed as objectives. In this respect, it focuses on targets, standards and performance measures or indicators. It is based on the agreement of role requirements, objectives, performance improvements and personal development plans. It provides the setting for ongoing dialogue about performance which involves the joint and continuous review of achievements against objectives, requirements and plans. Armstrong (2009) suggests that performance management should be something that is done for the people and in partnership with them. Selden et al. (2011) noted that performance management process is subject to interpretation by individual employees.

The term Performance Appraisal (PA) refers to the methods and processes used by organizations to assess the level of performance of their employees. This process usually includes measuring employees' performance 
and providing them with feedback regarding the level and quality of their performance (Denisi and Pritchard, 2006). The main goal of the PA in organizations is to improve employee performance. This goal could be achieved through three possible mechanisms: first, the information provided by the PA can be used for administrative decisions linking the evaluated performance to organizational rewards or punishments such as a pay raise, promotion, or discharge (Cleveland et al., 1989). Second, the PA process involves providing performance feedback to the employees who were evaluated, allowing them to adjust their performance strategies to match the desired performance. Lastly, the PA is a process that raises employees' awareness to the fact that they are being measured. The mere fact of knowing that one is being observed or measured increases performance and fosters cooperative behavior (Bateson et al., 2006).

\subsubsection{Performance Appraisal Systems: An Overview}

There is evidence in the history of PA that suggests formal performance appraisal began to materialize and be used in the evaluation of work performance as early as in the $20^{\text {th }}$ century from the time of the First World War (Fletcher \& Williams, 1992). Initially, PAs were used as a measure to raise morale of the workforce, the assumption was that high morale led to high productivity - a motion reinforced by Hawthorne studies in 1920s. However, the introduction of PA in the 1920s and 1930s was limited mainly to managers.

In the 1950s the potential usefulness of appraisal as a tool for motivation and development was gradually recognized and the number of companies using PA programs has risen since then (Fletcher and Williams, 1992). Hale and Whitlam (2000) asserted that as with many human resource systems, PA systems evolved out of a perceived requirement to institutionalize and centralize good human resource management practice. The systems were set up in order to support corporate decision-making, particularly for the purposes of salary review and promotion. The assumption was that line managers concentrated on their line activities and the human resource manager was interested in the people aspects of management. This led to the disempowering of the line manager and the abdication of good people management practices to the human resource department.

In the $1960 \mathrm{~s}$, it was recognized that a more systematic approach must be used and hence the introduction and development of a number of PA techniques including the popular technique called the MBO. But, although very logical in design, the system was less successful in practice because it was implemented mechanistically and that objectives were imposed on subordinates from above. Critics to MBO argue that the style was judgmental, and feedback would be given without the right to reply. By the end of 1960s, PA was generally seen as a more participative, problem solving process concentrated on task performance rather than personality (Fletcher and Williams, 1992).

The following decade saw a number of more specific development and an even greater shift towards openness and participation in appraisal, reflecting changes in society as a whole. Belief about the nature of human abilities, theories of motivation, trade union concerns, government legislation and changing social attitudes have all influenced and modified PA process (Fletcher and Williams, ibid). During the 1990s the evident difficulties of assessment and appraisal as isolated activities resulted in growing shift in performance management and the need to link the requirement of business strategy to all employees (Fletcher and William, ibid). Unlike earlier PA systems where the application of the systems were limited to the managers, there were trends to broaden the application of PA systems to employees in most job roles, and making PA much more than a top-down only process. It is commonly accepted that PA is more effective if an appraisee have more involvement in the review of his own performance (Hale and Whitlam, 2000).

In addition, with the development in upward appraisal, whereby the subordinate actually appraises the performance of the boss, PA has become even more democratized. Some observations on the development of PA practice concluded that the changes that have taken place in the field of PA demonstrate the fact that activities in this area reflect wider changes in societies as a whole. As societies have become more open and less rigid, so has PA. The PA has developed from becoming the sole concern of top management to being something that the appraisees, the trade unions and the government have a say in (Fletcher and Williams, 1992).

\subsubsection{Performance management in Tanzania Public Service: Background and Context}

The cradle of Performance Management (PM) in Tanzania public service is the reform agenda. Since 1961 when Tanzania attained her political independence, the government took deliberate actions to reform the civil (public) service in order to spearhead development in the economic and social spheres to respond to the expectations of the people. The public service was viewed as a strong arm of the government as well as engine for growth and development and was expected to ensure that the war against three development enemies was executed to a successful end (Bana, 2009).

According to Rugumyamheto (2005) Tanzanian government actions to reform the civil/public service in Tanzania since independence can be grouped in to four phases: first is the period following the independence (1962 to 1970), second is the decentralization phase (1972 to 1984), third is the structural adjustment civil service reform phase (1987 to 1999), and last is the fourth and current public service reform program phase which started in the year 2000. PM elements entered in the reform agenda in 2000 when the government launched Public Service Reform Programme (PSRP). 
According to Bana, (2009) PM constitutes the kernel of Tanzania PSRP which is implemented in ministries, independent departments and agencies as well as public sector in its entirety. The PSRP is implemented by the government of Tanzania in order to improve the MDA's service delivery, policy management and regulatory functions through a more vigorous and rigorous public service. PM in Tanzania is geared at improving the efficiency and effectiveness in public service delivery, consequently ensuring value for money. Performance management system is one of the reform initiatives that provide a means to improve the effectiveness of the MDA's by linking and aligning individual, team and the public service objectives and results (Bana, ibid).

PM in Tanzanian public service is supported by public service management and employment policy of 1999 and the Public Service Act No. 8 of 2002. These two instruments facilitate the institutionalization of PM system in the public sector, for example the policy stipulated clearly the need for performance and result oriented management philosophy in the public service. The Act also provides an enabling legal framework for managing performance in the public service.

The public service reform programme introduced a number of processes, tools and mechanisms in order to facilitate the institutionalization of PM system. The specific tools include strategic and operational planning, client service charters, service delivery surveys, self-assessment programs, performance budgets, the introduction of OPRAS and CMES (Bana, 2005). OPRAS was introduced in 2004. The tool aligns the objectives of the individual officer with that of the department or unit to the objectives of the organization. It is used in all public organizations.

The OPRAS replaced the CACRS which was used before in order to assess the performance of employees in the public service institutions (Bana, ibid). The CACRS was limited and largely generated one side information on the performance of employees in the public service. OPRAS, on the contrary, provide an opportunity to public servants and their managers to develop personal objectives based on strategic planning process and the organization's respective service delivery targets. In developing individual performance objectives both the appraisee and the appraiser have to agree on performance objectives, targets criteria and required resources. Also there must be mid-year review which is important in order to keep track of employees' performance progress. Public service legislation made OPRAS as mandatory to all MDAs. Local governments as part of public service have come under increasing pressure to modernize, to improve overall performance and service delivery, cost reduction, competition and to increase accountability to their stake holders (Guthrie and English, 1997).

\subsubsection{OPRAS: Understanding the Concept}

The OPRAS was adopted by the Tanzanian government in July 2004. This is a distinguishing tool in the history of human resource management in the Tanzanian public service. OPRAS is one of the major tools critical to the adoption and nurturing of the PM culture in the Public Service (Shitindi and Bana, 2009:12).

The OPRAS is the method through which the expectations of interest to both (employee and the organization) can be met at self-control. With this method, both supervisors and subordinates discuss the goals and objectives which are then communicated and mutually agreed by both parties. Subjectivity is highly reduced by this tool, while motivation and organization effectiveness is strengthened.

Tom (2004) posited that, in recent years open performance appraisal has been driven more by large scale organizational changes rather than theoretical advances in the study of PA. The advent of downsizing, decentralization and delaying flexibility of the public workforce, the move to team working and after wave of culture change programs and the new managerial initiatives such as Total Quality Management (henceforth TQM), competence and particular investors in people, have triggered the OPRAS.

This is the tool that aligns objectives of the individual officer with that of the department, division, unit or section to the overall strategy and objective of the organization used in all public service institutions, (PO-PSM, 2006:1). The main goal of OPRAS is to maximize organizational performance through a process of continuous improvement, which entails conducting performance reviews that focus on the future rather than the past (Hartoget al., 2004). The OPRAS has different characteristics which distinguish it from other appraisal systems practiced in the past; hence making it more successful and capable performing tool to be pursued by public organizations (Sylvester, 2010).

\subsubsection{OPRAS Unique Features}

PO-PSM (2006) highlighted the following unique features of OPRAS that can be used to differentiate it from the previous confidential appraisal system: (i) Openness- allows both employee and employer to discuss and agree on the organizational and individual objectives that are to be achieved during the year openly; (ii) Participation involves employees in the process of setting objectives, performance targets and criteria as well as determining, assessing and recording performance; (iii) Accountability- individual employees are required to sign annual performance agreements and account for their performance against agreed targets and resources allocated for each activity; (iv) Ownership-shows linkage between individual objectives and the overall organizational objectives in a given period. This helps the employee understand own role and contribution thus creating commitment in achieving organizational goals; and (v) Feedback - employees must be informed about the 
method and purpose of the PA and also be notified probably orally or writing about the results of their performance.

\subsubsection{Importance of OPRAS}

PO-PSM (2006) identified the following benefits of OPRAS to the employee and employer:

(a) To Employee - (i)Is motivated to perform effectively and continuously to improve performance due to recognition; (ii) Is empowered through resources provided to implement planned and agreed activities; (iii) Is informed of skill gaps and measures for improvement; (iv) Is guided and focused in the execution of duties and responsibilities; (v) Improved working relations with both higher and lower levels; (vi) Improves transparency; and (vii) Enables the employees to know what is expected of them.

(b) To Employer - (i) Is provided with opportunities to re-enforce the organizational objectives; (ii) Is given feedback on the effectiveness or weaknesses of workplace systems, processes and procedures; (iii) Informed on how to make merit based decisions on rewards and sanctions; (iv) Informed on staff developmental needs and human resources planning; (v) Improved working relations in an organization; and (vi) Assisted to confirm and promote an employee whenever necessary.

\subsection{Empirical literature Review}

This part reviews various studies done by other researchers on the topic understudy. It looks at their findings and conclusions so that at the end these are compared with the results of this study in order to analyze the gap for this study. Songstad et al (2012) conducted a study which aimed to assess the performance enhancement tools in public health workers. The study revealed that there is a general reluctance among health workers towards OPRAS as health workers did not see OPRAS as leading them to financial gains nor did it provide feedback on performance.

The study conducted by Mpanda (2015) revealed that OPRAS has great important features that can be used in the process of identifying employees' training needs. Despite the government efforts to introduce the systematic procedures in conducting training, issues of training needs identification are neglected. This state of affairs has continuously led to presence of training which does not reflect the need for job and organization in general in public sectors. Baraka (2015) in his study revealed that results of OPRAS exercises do not necessarily lead to either promotion or salary increase or training opportunities. This has led to employees believe that the exercise is not geared to help employees but rather be used as a weapon by supervisors. The study further asserts that majority of workers believe that OPRAS results have no impact at all to their performance levels. The assessment conducted by the Government of Tanzania (2011) also found that "whereas implementation of OPRAS is mandated by the law, its uptake has been slow. As observed through this assessment, operationalization of OPRAS is at various levels. In the majority of MDAs, OPRAS is implemented at Directors and Assistant director's level. It has yet to cascade the other lower levels. I addition, the mid-year reviews are not happening in the majority of MDAs.

\section{Methodology}

\subsection{Research design}

To achieve its objectives a case study design was adopted. Aakeret al., (2002) defined a case study as a comprehensive description and analysis of a single situation. In addition, the case study approach place emphasis on a fully contextual analysis of fewer events or conditions and their interactions (Cooper and Schindler, 2003).

This study design was adopted because it brings the inner sights and it enables the researcher to make a comprehensive inquiry into the nature of the phenomenon. Also, using this type of research design facilitates generalization to other cases not covered by this study and creates a base for replication of the study using large sample of cases. Moreover, case study designs allow various data collection methods to be employed such as interview and questionnaire so as to come up with the data required to answer the research objectives and thus validate the generalization at the end.

The study also used both qualitative and quantitative design. A qualitative research design is a method used to find out how people feel or what people think about a particular subject or institution, where quantitative research design is based much on the measurements of quantity or amount (Kothari, 2004). Hence, quantitative research design was used in calculating simple percentage and number of respondents. Therefore this is a mixed research design which use both qualitative and quantitative.

\subsection{Study Population, sample size and sampling technique}

The targeted population of this study was employees of Iramba District Council at its head office. IDC was selected as a focal point of this study because it one of the old local government authority in Singida Region and have been practicing performance appraisal for many years therefore it was easy to collect reliable information relating to performance management. The council has total number of 98 employees working at its head office. The Questionnaires were distributed to all employees who were present in their offices at the time when survey 
was conducted. These comprised heads of departments, administrative and technical staffs in deferent departments. The study intended to have a clear picture by involving all kinds of employees. A random sampling technique was employed and employee's register was used as a study sampling frame. 90 questionnaires were distributed to respondents and 80 of them were collected this make the respondent rate to be $90 \%$.

\subsection{Research instruments}

Data were obtained through a set of questions that were drawn up to meet the objective of this study. As set of questions were designed in which the respondents were required to fill in the answers. Properly constructed questionnaire in English language was prepared and administered to respondents who were the employees of IDC. An interview was also used to collect qualitative data which could not be collected through questionnaires. Furthermore the study needed a deep explanation on some matters with relation to the research problem.

\subsection{Ethical Approval}

Ethical clearances for this study were granted by the Regional Administrative Secretary (RAS) from Singida region. Moreover, verbal consent was also sought from the study respondents.

\subsection{Results and Discussions}

The objective of this study was to review whether the OPRAS as a performance management tool as currently used in IDC is adequate for improving employees' performance. Therefore, in order to gather data for this objective respondents were presented with statements and required to show their level of agreement and disagreement. The statements and the findings (see Table 1) are presented as follows:

The first statement presented to respondents was related to their awareness of the organization goals. The findings reveal that majority $48.8 \%$ of the respondents were satisfied with the statement that I am aware of the organization goals. $36.3 \%$ of the respondents were neutral about their awareness of the organization goals. The remaining $15.1 \%$ of the respondents were dissatisfied with their awareness about the organization goals. Moreover during interview it was also revealed that majority of the respondents agreed that they were aware about the strategic objectives of the organization.

The second statement respondents were required to indicate their level of agreement whether they have knowledge about what is expected from them in their jobs. The findings indicate that majority of the respondents $78.8 \%$ were satisfied with the statement. The second portion $12.8 \%$ were neutral and the remaining $8,8 \%$ were dissatisfied. The results from interview also indicated the same results that majority of the respondents were aware about what is expected from them in their jobs.

Third statement was concerned about the knowledge of the respondents about the performance standards. The results indicate that majority of respondents $71.3 \%$ were satisfied with their knowledge about the performance standards. $22.5 \%$ were neutral and the remaining $6.3 \%$ were dissatisfied with the statement. These results are agreeing with those from interview where majority of respondents agreed that they were aware about the performance standards.

The next statement respondents were asked about their level of agreement on the contribution of OPRAS as a tool of managing performance in developing key competences among employees. The result shows that $45.1 \%$ of the respondents were dissatisfied $32.5 \%$ of the respondents were dissatisfied and the remaining $22.8 \%$ of the respondents were neutral. These results do not match with the results from the interview where majority of the respondents were dissatisfied with the contribution of OPRAS in developing key competencies among employees. This implies that OPRAS as a tool of managing performance in the Tanzanian Public Service as currently used at IDC do not contribute much to the development of key competences among employees.

The respondents also were also required by this study to provide their level of agreement whether they feel part of the decision making process. This was purposely asked due to the reason that OPRAS provides an opportunity for the employee's and their supervisors jointly plan for the goals and the means to achieve them. The findings indicate that majority of respondents $43.8 \%$ were satisfied with their level of participation. $32.5 \%$ of the respondents were neutral and the remaining $23.8 \%$ were dissatisfied with their level of participation in the decision making. The results from interview revealed that majority of respondents were not satisfied with their level of participation.

The subsequent statement respondents were asked to provide their level of satisfaction with their feeling with the goals from OPRAS. The findings revealed that $50 \%$ of the respondents were satisfied that they feel committed with OPRAS goals $27.5 \%$ were neither dissatisfied nor satisfied and the remaining $22.9 \%$ were dissatisfied.

The next question was about how well OPRAS inspires employees at IDC to exercise their rights. The results show that majority of respondents $55.5 \%$ were dissatisfied with the statement. $26.3 \%$ were neither dissatisfied nor satisfied and the remaining $18.8 \%$ were satisfied. These results are the same with those from interview in which majority of respondents do not agree that OPRAS as currently used at IDC inspires them to 
exercise their rights.

The respondents were also asked to provide their opinions regarding the frequency of receiving feedback from their supervisors. The results revealed that majority of them $63.8 \%$ were not satisfied with the frequency of receiving feedback from their supervisors. $26.3 \%$ were neither satisfied nor dissatisfied and the remaining $10.1 \%$ were satisfied. The results above correspond with those from interview in which majority of respondents said that they don't receive regular feedback from their supervisors. This is against with the tool itself since it requires supervisors to provide regular feedback to their employees.

In question 9 respondents were asked to provide their opinion whether OPRAS as a tool used to manage performance in the public service of Tanzania helps them to set and achieve meaningful objectives. The results indicates that majority of the respondents $51.3 \%$ were dissatisfied $26.3 \%$ were neutral $22.6 \%$ were satisfied. These results are the same with those from interview. This imply that OPRAS as a tool of managing performance in public service of Tanzania do not help employees set and achieve meaningful goals in the study area, IDC.

The last question respondents were asked to provide their degree of agreement with the general statement whether OPRAS as currently used at IDC is a useful tool to enhance employee's performance. The results emerged from this question shows that majority of respondents $51.3 \%$ were dissatisfied. $23.8 \%$ were neutral and the remaining $25 \%$ were satisfied. The results are the same with those from interview where majority of respondents were in the view that OPRAS as currently used at IDC is inadequate at improving employee's performance.

The most obvious finding that emerges from this study is that OPRAS as currently used at IDC is not adequate tool to improve employee's performance. These findings augur well with the earlier assessment of OPRAS conducted by the Government of Tanzania in the year 2011 which observed that OPRAS in majority of MDAs is not implemented as it was designed. The findings also support the earlier studies conducted in Iramba District Council by Adallah (2013), Morogoro Municipal Council by Sendoro (2013) and Monduli and Meru Hospitals by Dickson (2013).

\subsection{Conclusion, Recommendations and Areas for Further Research}

\subsection{Conclusion}

the results of this study which was aimed at exploring the influence of OPRAS on employees' performance show that OPRAS as currently used in IDC is not adequate at improving employees' performance. This is contrary to the aim of its establishment which was to improve organizational performance by linking the individual goals with that of the organization.

\subsection{Recommendations}

The results obtained from this study indicate that OPRAS as currently used in IDC is not adequate at improving employees' performance. This study, therefore, offers the following recommendations to be considered by IDC for successfully implementation of OPRAS that could result into improved employees' performance and the council in general.

i. Performance planning should not be always a sole activity of supervisors and higher officials but include the active involvement of employees during the design and implementation of the plan as it is a crucial element of OPRAS success. In addition, IDC has to create an environment where employees can prepare their own SMART goals, participate in the discussion and take ownership of the plan agreement. This can make employees feel that they own the process and being more committed to the goals from OPRAS forms. The council also should create a room for the practice of setting goals and standards of performance measures on the basis of mutual agreement between employees and supervisors and let employees agree on the goals they are expected to achieve and the standards which they will be evaluated. The act of jointly setting goals and standards will provide a clear direction in the form of increasing effort, persistence towards goal accomplishment and have some motivational benefits.

ii. The appraisal process must be viewed as a continuous activity rather than a oneyear event. Performance expectations and actual performance must be discussed often and regularly. There should be an ongoing communication throughout the year between supervisors and subordinates in order to identify the areas of weaknesses and address them before the end of performance year.

iii. The successful implementation of OPRAS in IDC, among other things, requires the commitment of top leaders of the council especially District Executive Director (DED) and heads of departments. The top leaders should emphasize and support the system goals and objectives by encouraging training of the system to the public servant and involve them in setting their goals and standard of their performance.

iv. Training is required especially in areas of setting objectives and filling in the OPRAS forms from top management to lower cadres. This will help the management and the employees in IDC to have a full understanding of the tool hence its implementation will be easy and effective. 


\subsection{Areas for Further Research}

Because this study was restricted to a single local government authority which is IDC, therefore, future research on this subject could focus on extending the studies of this nature to a wide range of public organizations so as to include diverse respondents.

\section{REFERENCES}

Aaker et al., (2002): Marketing Research (7th Ed), New Delhi, John Wiley

Armstrong M., (2000), Performance Management, Key Strategies and Practical Guidelines, Second Edition, UK, Kogan Page Limited.

Armstrong, M. (2009).A Handbook of Human resource management practice. 11th edition.Cambridge University Press.

Bana, B (2009) Performance Management in the Tanzania Public Service: A paper Presented at the Conference on Governance Excellence:' managing Human Potential' Held at Arusha International Conference Centre, United Republic of Tanzania, from $2^{\text {nd }}-4^{\text {th }}$ March 2009.

Baraka M (2015) The role of Performance Appraisal System on Individual workers performance in Public Organizations (Master thesis, Mzumbe University)

Baron, A. (2004) Managing Performance: Performance management in action. London: CIPD.

Bateson, M., Nettle, D., \& Roberts, G. (2006).Cues of being watched enhance cooperation in a real-world setting. Biology Letters, 2, 412-414

Beer, M \&Ruh, R.A (1976): Employee Growth Through Performance Management: Havard Business Review, pp. 59-66

Brannen J, (2012) Mixing Methods: Qualitative and Quantitative Research. The University of Michigan, USA

Buchner, T.W (2007) Performance Management theory: A look from the Performer's Perspective with its Implications for HRD. Human Resource Development International, Vol. 10 ,Iss. 1,2007

Cleveland, J.N., Murphy, K.R., \& William, R.E. (1989). "Multiple Uses of Performance Appraisal: Prevalents and Correlates".Journal of applied Psychology.Vol. 74. No. 1, 130-135.

Cooper, D.R. and Schindler, P.S. (2003) Business Research Methods. 8th Edition, McGraw-Hill Irwin, Boston.

Davis, S., \& Albright, T. (2004).An investigation of the effect of balanced scorecard implementation on financial performance.Management accounting research, 15(2), 135-153.

DeNisi A S Pritchard R D (2006) Performance appraisal performance management and from AML 3031 at University of Florida.

Fletcher, C. and Williams, R. (1992) Performance Management in the UK: Organizational experience. London: IPM.

Gall et al. (1996).Educational Research: An Introduction. New York: Longman Publishers

Gall, D.M.,Borg,N.R., and Gall, J.P (1996). Educational Research: An Introduction. New York: Longman Publishers.

Gomez-Mejia, L. R., Nuñez-Nickel, M., \& Gutierrez, I., 2001. The Role of Family Ties in Agency Contracts. Academy of Management Journal, 44: 81-96.

Guest, D. (1999) Human Resource Management _ the workers verdict, Human Resource Management Journal, vol. 9(3), pp.5-25.

Guthrie, J and English, L (1997) Performance Information and Programme Evaluation in the Australian Public Sector; International Journal of Public Sector Management, 10(3), pp.154-164;

Hale, R.; Whitlam, P. 2000. Powering up performance management: An integrated approach to getting the best from your people. Brookfield, VT (USA): Gower. ISBN 056608189X

Hildebrand, R. (2007) 'Measuring and Managing Performance in Local Government: A Literature Review; Working Paper Series, University of Victoria.

Kombo\&Tromp. (2006) Methodology of Research in Social sciences. Delhi, Himalaya Publishing House International (P) LTD.

Kothari, (2004): Research Methodology-Methods and Techniques, New Age

Krishnaswami, O. (2002). Methodology of Research in Social Science. Delhi: Himalaya.

Macky,K.,\& Johnson, G. (2000).The strategic Management of Human Resources in New Zealand. Auckland, New Zealand: Irwin/McGraw-Hill

Mpanda I (2015) Effectiveness of Open Performance Review and Appraisal system in Identifying Training needs (Master Thesis, Mzumbe University)

Msemo, R (2011) The assessment of Effective Implementation OPRAS system in Public Service in Tanzania: Case study President's Office Public service Management (Master Thesis KDI school of Public Policy and Management

Ngumuo, S \& Wang, M (2015) Measuring Performance in Public Sector Organizations: Evidence from Local Government Authorities in Tanzania; European Journal of Business and Management. Volume, 7 No. 9, pp. 
184-194

Panda, S (2011) Performance Management system: Issues and Challenges; Journal of Management Studies; Volume 36 No.3

Purcel, J et al (2003) Understanding People and Performance Link: Unlocking the Blackbox Research Report. London: CIPD

REPOA, (2008).Local Autonomy and Citizen Participation in Tanzania from a Local Government Reform Perspective, Dar es Salaam: MkukinaNyota Publishers.

Rugumyamheto, J. (2005) Performing the Public Service in Tanzania: A critical Prerequisite to Economic Growth, Health Creation and Poverty Reduction; Paper Presented at AAPAM annual Roundtable Conference, held at Mombasa, Kenya from $7^{\text {th }}-11^{\text {th }}$ March, 2005.

Saunders, M; Lewis, P and Thornhill, A. (2012). Research Methods for Busness Students. (6th, Ed.) RotoritoItaly: Pearson Education Ltd.

Selden, S \& Sowa J,E. (2011) Performance Management and Appraisal in Human Service Organizations: Management and Staff Perspectives; Public Personnel Management Volume 40 No.3 Fall 2011

Songstad NG, Moland KM, Massay DA, Blystad A: Why do health workers in Tanzania prefer public sector employment?. BMC Health Serv Res. 2012, 12: 92-10.1186/1472-6963-12-92.

Stevers, B.P and Joyce,T. (2000), "Building a balanced performance management system" SAM Advanced Management Journal,Vol.8.

Sulle, A, (2014) The use of Performance Measurement Information in the Tanzania Public Sector: The case of National Housing Corporation: International Journal of Management Science and Business Research, Vol-3, Issue 7.

Tom C (2004), Performance Management and Public Sector Reform: The Norwegian Hospial Reform».

United Republic of Tanzania (1999).Public Service Management and Employment Policy, Dar es Salaam: POPSM

United Republic of Tanzania (2002) Public Service Act

United Republic of Tanzania (2003).Public Service Amendment Act of 2007, Dar es Salaam: Government Printer.

United Republic of Tanzania (2005).Public Service Reform Programme- Phase Two (PSRP II (2008-2012), Dar es Salaam: PO-PSM

URT (2004).Installation of performance Management systems in ministries and Independent Departments, Presidents office, Public Service Management, Tanzania.Unpublished paper.

URT.(2011) OPRAS Guideline

World Bank (2008) Implementation Completion and Results Report for a Public Service reform Project (IDA33000 IDA 3300AI: Dar es Salaam.

Yeasmin, S \&Rahman K, (2012). Triangulation Research Method as the Tool of Social Science Research.BUP journal, 1(1), 154-163.

Table 5: Respondent's level of agreement whether OPRAS is adequate to improve employee's performance as currently used at Iramba district Council

\begin{tabular}{|c|c|c|c|c|c|c|c|c|c|c|c|c|}
\hline No & Statement & HD & & D & & $\mathbf{N}$ & & 5 & & IS & Mean & SD \\
\hline & & $\%$ & $\bar{F}$ & $\%$ & $\mathbf{F}$ & $\%$ & $\mathbf{F}$ & $\%$ & 1 & $\%$ & & \\
\hline 1 & I am aware of the organization goals & 11.3 & & 3.8 & 29 & 36.3 & 25 & 31.3 & & 17.5 & 3.4 & .165 \\
\hline 2 & $\begin{array}{l}\text { I know what is required of me in my } \\
\text { job }\end{array}$ & 0 & & 8.8 & 0 & 12.5 & & 47.5 & 5 & 31.3 & 4.01 & 893 \\
\hline 3 & $\begin{array}{l}\text { I know what my performance } \\
\text { standards are }\end{array}$ & 2.5 & 3 & 3.8 & 3 & 22.5 & & .0 & & 2 & 3.84 & 2 \\
\hline 4 & I have developed key competences & 2.5 & 24 & 30.0 & 18 & 22.5 & 23 & 28.8 & 13 & 16.3 & 3.26 & .133 \\
\hline 5 & I feel part of decision making process & 13.8 & 8 & 10.0 & 26 & 32.5 & 23 & 28.8 & 12 & 15.0 & 3.21 & 1.229 \\
\hline 6 & $\begin{array}{l}\text { I feel committed with the goals from } \\
\text { OPRAS }\end{array}$ & 13.8 & 7 & 8.8 & 22 & 27.5 & 26 & 32.5 & 4 & 17.5 & 3.31 & .259 \\
\hline 7 & $\begin{array}{l}\text { I think OPRAS inspires me to } \\
\text { exercise my rights }\end{array}$ & 2 & & 28.8 & & 26.3 & & & & 5.0 & 3.31 & .259 \\
\hline 8 & $\begin{array}{l}\text { I am always getting feedback from } \\
\text { my supervisor }\end{array}$ & 2 & & 25.0 & & & & 8 & & 6.3 & 2.43 & 167 \\
\hline 9 & $\begin{array}{l}\text { I believe OPRAS helps me to set and } \\
\text { achieve meaningful objectives }\end{array}$ & 13 & & 30.0 & & 2 & & 21.3 & & 6.3 & 71 & 0 \\
\hline 10 & $\begin{array}{l}\text { In general I found OPRAS as } \\
\text { currently used in IDC a useful tool to } \\
\text { enhance my performance }\end{array}$ & $\begin{array}{lll}17 & 21.3\end{array}$ & & & & & & & & & & \\
\hline
\end{tabular}

HD=highly dissatisfied, $D=$ Dissatisfied, $N=$ Neutral, $S=$ Satisfied, $H S=$ highly satisfied and

$\mathrm{SD}=$ Standard deviation 